\title{
Thermal characterization and analysis of phase change random access memory
}

\author{
V. Giraud, J. Cluzel, and V. Sousa \\ Conmissariat á l' Energie Atomique-Direction de la Recherche Technologique-Laboratoire d'Electronique \\ de Technologie de l'Information-Commissariat á l'Energie Atomique/Grenoble (CEA-DRT-LETI-CEA/ \\ GRE)-17, rue des Martyrs, F-38054 Grenoble cedex 9, France \\ A. Jacquot, ${ }^{\text {a) }}$ A. Dauscher, B. Lenoir, and H. Scherrer \\ Laboratoire de Physique des Matériaux, Unité Mixte de Recherche-Centre National de la Recherche \\ Scientifique-Institut National Polytechnique de Lorraine-Université Henri Poincaré \\ (UMR CNRS-INPL-UHP) 7556, Ecole Nationale Supérieure des Mines de Nancy, \\ Parc de Saurupt, F-54042 Nancy, France. \\ S. Romer \\ Department 125, Eidgenössische Materialprüfungs- und Forschungs Anstalt (EMPA)-Swiss Federal \\ Laboratory for Materials Testing and Research, Überlandstrasse 129, CH-8600 Duebendorf, Switzerland
}

(Received 21 March 2005; accepted 6 May 2005; published online 7 July 2005)

\begin{abstract}
The cross-plane thermal conductivity of $\mathrm{Ge}_{2} \mathrm{Sb}_{2} \mathrm{Te}_{5}$, either in its amorphous state or fcc crystallized state, and titanium nitride (TiN) thin films has been measured at room temperature by the $3 \omega$ method. These materials are involved in the fabrication of phase change random access memory (PC-RAM), $\mathrm{Ge}_{2} \mathrm{Sb}_{2} \mathrm{Te}_{5}$ and TiN being the PC and pseudoelectrode materials, respectively. The thermal conductivity of insulating $\mathrm{SiO}_{2}$ and $\mathrm{ZnS}: \mathrm{SiO}_{2}$ layers was determined too. Each thermal conductivity measurement was performed by the means of at least two strip widths in order to check both the measurement self-consistency and the measurement accuracy. The performance of PC-RAM cells, i.e., the time needed to reach the melting temperature of the PC material and the cooling speed, has been evaluated as a function of both the measured thermal conductivity of the PC material and the reset current intensity independently of the thermal properties of the pseudoelectrodes by the way of analytical formula. The influence of the thickness and the thermal properties of the pseudoelectrodes on the performances have been determined by numerical simulations. (C) 2005 American Institute of Physics. [DOI: 10.1063/1.1944910]
\end{abstract}

\section{INTRODUCTION}

Phase change random access memories (PC-RAMs) are nonvolatile memories using $\mathrm{PC}$ materials, whose crystallographic structure can be reversibly switched between an amorphous state and a crystalline state. The amorphous-tocrystalline transition is accompanied by a drop of three orders of magnitude of the electrical resistivity that can be used to store information. This emerging type of memories may combine the speed of digital random access memories (DRAM) and the nonvolatility of flash memories while their lifetime cycle $\left(10^{12}\right)$ is much better. ${ }^{1,2}$

The building block of a conventional PC-RAM is shown in Fig. 1(a). The PC material is sandwiched between two high thermally conductive electrodes generally made of metals such as copper or tungsten. An electrical current of moderate intensity sustained long enough to trigger the amorphous-to-crystalline transition is used to write the information. A pulse of electrical current of high intensity is used to erase the information by bringing the material back to its amorphouse state by a melting-quenching process. An interesting PC material is $\mathrm{Ge}_{2} \mathrm{Sb}_{2} \mathrm{Te}_{5}$. This compound, located on the $\mathrm{GeTe}-\mathrm{Sb}_{2} \mathrm{Te}_{3}$ pseudobinary line, possesses great crystal-

\footnotetext{
${ }^{a)}$ Author to whom correspondence should be addressed; electronic mail: alexandre.jacquot@mines.inpl-nancy.fr
}

lization speeds. ${ }^{3}$ It has also been used for optical storage ${ }^{4}$ [digital versatile disk (DVD)-RAM] or probe mass storage. ${ }^{5}$

Nowadays, the key objectives in phase change recording device research are to increase the writing and erasing speeds, to increase the information density, and to decrease the energy consumption. ${ }^{6}$ It can be achieved by lowering the thermal conductivity of the crystallized $\mathrm{Ge}_{2} \mathrm{Sb}_{2} \mathrm{Te}_{5}$ through a careful choice of the annealing temperature but also by thermally isolating the PC material. This constrain can be realized through sandwiching the PC material between two low

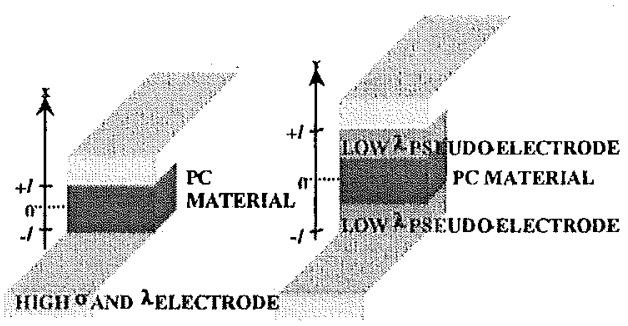

(a)

(b)

FIG. 1. Overview of a PC-RAM Structure. (a) Conventional PC-RAM structure: the phase change material is sandwiched between two electrodes of high thermal conductivity $(\lambda)$ and electrical conductivity $(\sigma)$. (b) PCRAM structure: two layers (psendoelectrode) made of a material with a low thermal conductivity and relatively good electrical conductivity are introduced between the PC material and each electrode. 
thermal conductive pseudoelectrodes such as titanium nitride (TiN) [Fig. 1(b)]. Another advantage of these pseudoelectrodes is to prevent species diffusion. Consequently, it is of the uppermost importance to measure the thermal conductivity of the phase change material and of the pseudoelectrodes in order to optimize the design, the geometry, and the materials used in the stacks of PC-RAM menories.

In this paper, the thermal conductivities of the phase change material $\left(\mathrm{Ge}_{2} \mathrm{Sb}_{2} \mathrm{Te}_{5}\right)$, either in its amorphous or crystalline state, and of the TiN pseudoelectrodes have been measured by the $3 \omega$ method. The thermal conductivity of $\mathrm{SiO}_{2}$ and $\mathrm{ZnS}-\mathrm{SiO}_{2}$ thin films has also been considered. $X$-ray diffraction (XRD) was applied to identify the crystallographic structure of the PC material. The influence of the thermal conductivity of crystallized $\mathrm{Ge}_{2} \mathrm{Sb}_{2} \mathrm{Te}_{5}$ in the rocksalt structure (fcc) on the time needed to reach the melting temperature and on the cooling speed has been investigated by using analytical formula. The geometry of the PC-RAM cells, i.e., the thickness of the electrodes, has been optimized by numerical simulations.

\section{THERMAL CONDUCTIVITY MEASUREMENTS}

\section{A. Measurement procedure}

The $3 \omega$ method $^{7-9}$ was used to measure the cross-plane thermal conductivity at $T=300 \mathrm{~K}$ of the prepared films. Briefly, this dynamic technique uses a thin metal strip deposited on the surface of the sample to be analyzed, that acts both as an electrical heater and a thermometer. At a given heating power, the temperature rise measured on the metal strip is a function of the underlying material properties (density, thermal conductivity, and heat capacity), the geometry (thickness of the films and width of the strip), and of the measurement parameters (frequency and intensity of the driving current). This measurement method is particularly well suited for the measurement of the cross-plane thermal conductivity of thin electrically insulating films. If the thermal conductivity of an electrically conducting film has to be investigated, as it is the case for TiN and the PC material, an additional insulating layer between the film and the metal strip is required. The insulating layers were $\mathrm{SiO}_{2}$ and $\mathrm{ZnS}: \mathrm{SiO}_{2}$ for TiN and $\mathrm{Ge}_{2} \mathrm{Sb}_{2} \mathrm{Te}_{5}$, respectively.

The temperature rise of the heater due to the substrate was derived using Lee and Cahill's formula under the assumptions that the thermal wave penetration depth is far larger than the strip width. ${ }^{8}$ The thermal conductivity, heat capacity, and density used to calculate the temperature amplitude due to the $\mathrm{Si}$ substrate are $150 \mathrm{~W} \mathrm{~m}^{-1} \mathrm{~K}^{-1}$, $711 \mathrm{~J} \mathrm{~kg}^{-1} \mathrm{~K}^{-1}$, and $2330 \mathrm{~kg} \mathrm{~cm}^{-3}$, respectively. ${ }^{9,10}$

For an insulating film-on-substrate sample, the total temperature rise at the heater is composed of two parts: one is the temperature rise in the substrate and the other is the temperature drop across the insulating film. If the metal line is wide compared to the thickness of the film, the film simply adds a frequency-independent thermal resistance: ${ }^{8}$

$$
\Delta T=\frac{P_{l} e}{2 b \lambda}
$$

where $P_{l}$ is the heating power input to the strip per unit of length, $2 b$ the strip width, $e$ the film thickness, and $\lambda$ the cross-plane thermal conductivity of the film.

In the case of our structures (insulating film/conductive film/Si substrate), the conductive layer adds another thermal resistance. By measuring separately the thermal conductivity of the insulating layer $\left(\mathrm{ZnS}: \mathrm{SiO}_{2}\right.$ and $\left.\mathrm{SiO}_{2}\right)$, the additional thermal resistance due to the conductive layer can be deduced from the subtraction of the thermal resistance of the insulating layer to the total thermal resistance of the structure.

The temperature coefficients of resistance (TCR) of the metal strip were measured on each sample with a dedicated experimental setup by measuring the electrical resistance from room temperature to $320 \mathrm{~K}$. The measurement of the thermal conductivity was carried out with a driving current of frequency $100 \mathrm{~Hz}$. The frequency is chosen to be large ellough so that the thermal wave penetration depth is smaller than the wafer thickness. The measurements of the thermal conductivity of each structure were carried out with at least two metal lines of different widths to check the consistency of the measurement. The strips on the photolithography mask were $20,10,5$, and $2 \mu \mathrm{m}$ in width. It was assumed that the error made on the widest strip is negligible. In order to control and to really estimate the width of the narrower metal lines, the ratio of the electrical resistance per unit of length of the metal line to the electrical resistance per unit of length of a 20 - $\mu \mathrm{m}$-wide metal line was calculated. This procedure was validated by the measurement of the metal linewidth by scanning electron microscopy.

As a rule of thumb [see Eq. (1)], narrow metal hines are better suited to measure thin films because when the width of the strip decreases, the contribution of the film to the temperature rise increases. The use of narrow strips is recommended, especially when the thermal contrast between the film and the substrate is low.

\section{B. Samples fabrication}

The films to be measured $\left(\mathrm{SiO}_{2}, \mathrm{ZnS}: \mathrm{SiO}_{2}, \mathrm{SiO}_{2} / \mathrm{TiN}\right.$, and $\mathrm{ZnS}: \mathrm{SiO}_{2} / \mathrm{Ge}_{2} \mathrm{Sb}_{2} \mathrm{Te}_{5}$ ) were deposited on silicon wafers, $4 \mathrm{in}$. in diameter and $525 \mu \mathrm{m}$ in thickness. Prior to deposition, the Si substrates were treated with hydrofluoric acid in order to remove the native oxide. Single $\mathrm{SiO}_{2}$ and $\mathrm{ZnS}(80 \%): \mathrm{SiO}_{2}(20 \%)$ composite layers were deposited by plasma-enhanced chemical-vapor deposition (PECVD) at a final temperature of $493 \mathrm{~K}$ and by radio-frequency face-toface magnetron sputtering ( $\mathrm{rf}$ sputtering) at $300 \mathrm{~K}$, respectively. The TiN films were prepared by reactive physical vapor deposition (PVD) from a Ti target under $N_{2}$ atmosphere without intentional heating of the substrate. These films were further covered by an insulating $\mathrm{SiO}_{2}$ layer prepared under the same experimental conditions as previously described. The $\mathrm{Ge}_{2} \mathrm{Sb}_{2} \mathrm{Te}_{5}$ films were prepared by if sputtering at 300 $\mathrm{K}$. As-deposited, the $\mathrm{Ge}_{2} \mathrm{Sb}_{2} \mathrm{Te}_{5}$ films are amorphous. An annealing process at $480 \mathrm{~K}$ during $30 \mathrm{~min}$ was used to achieve the crystallization of the $\mathrm{Ge}_{2} \mathrm{Sb}_{2} \mathrm{Te}_{5}$ films. During 
the annealing process, the thickness of the $\mathrm{Ge}_{2} \mathrm{Sb}_{2} \mathrm{Te}_{5}$ films is reduced by about $7 \% .^{11} \mathrm{ZnS}(80 \%): \mathrm{SiO}_{2}(20 \%)$ composite insulating layers were further deposited by rf sputtering on the top of amorphous and crystallized $\mathrm{Ge}_{2} \mathrm{Sb}_{2} \mathrm{Te}_{5}$ layers.

The metallic strips of different widths, acting as both heater and thermometer, feature four electrical contact pads. They were fabricated on the previously deposited single and multilayers by sputter depositing a 100 -nm-thick gold layer with a 20-nm-lhick titanium adhesion layer and by patterning them by ion-beam etching (IBE) using argon gas. All the strips were integrated on an area of $I \mathrm{~cm}^{2}$ in order to have no influence on the thermal conductivity measurements of potential film thickness inhomogeneities.

\section{MODELING OF PC-RAM}

\section{A. Conventional structure}

For the estimation of the temperature distribution during the writing and erasing of information in the PC-RAM cell shown in Fig. I, an analytical formula has been derived. The lateral heat losses are neglected so that the temperature distribution is a function of the position $x$ and time $t$, only. It is assumed that the electrical and the thermal conductivities of the electrodes are large enough so that the temperature in the electrode is constant and equal to room-temperature $T_{O}$. If heat is produced in the PC material at a rate $J^{2} / \sigma$ per unit volume, where $J$ is the electrical current density and $\sigma$ the electrical conductivity, respectively, and if it is assumed that the thermal and electrical properties of the PC material do not change with temperature, the temperature in the $\mathrm{PC}$ material is given by ${ }^{12}$

$$
\begin{aligned}
T_{1}(x, t)= & T_{0}+\frac{J^{2} l^{2}}{\sigma_{\mathrm{PC}} \lambda_{\mathrm{PC}}}\left\{1-\frac{x^{2}}{l^{2}}-\frac{32}{\pi^{3}}\right. \\
& \times \sum_{n=0}^{\infty} \frac{(-1)^{n}}{(2 n+1)^{3}} \cos \frac{(2 n+1) \pi x}{2 l} \\
& \left.\times \exp \left[-\kappa_{\mathrm{PC}}(2 n+1)^{2} \pi^{2} / 4 l^{2} t\right]\right\},
\end{aligned}
$$

where $\kappa_{\mathrm{PC}}, \lambda_{\mathrm{PC}}$, and $2 l$, are the thermal diffusivity, the thermal conductivity, and the thickness of the phase change layer, respectively.

At a time $t_{F}$ long enough to reach either the melting or the crystallization temperature of the phase change material, the electrical current is switched off and the temperature distribution for $t>t_{F}$ is given by

$$
\begin{aligned}
T_{2}(x, t)= & T_{0}+\frac{2}{l} \sum_{n=0}^{\infty} \exp \left[-\kappa_{\mathrm{PC}}(2 n+1)^{2} \pi^{2}(t\right. \\
& \left.\left.-t_{F}\right) / 4 l^{2}\right] \cos \frac{(2 n+1) \pi x}{2 l}\left[\frac{2 l(-1)^{n+1} T_{0}}{(2 n+1) \pi}\right. \\
& \left.+\int_{0}^{l} T\left(x^{\prime}, t_{F}\right) \cos \frac{(2 n+1) \pi x^{\prime}}{2 l} d x^{\prime}\right] .
\end{aligned}
$$

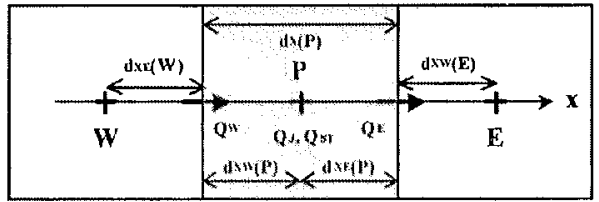

FIG. 2. Elementary cell centered on $P$ of the grid for numerical simulation of the heat transfer in PC-RAM. The cell is next to the cells centered on $E$ and $W$. The temperature $T_{p}$ is calculated from energy conservation $\left(Q_{E}\right.$ $\left.-Q_{W}+Q_{J}-Q_{\mathrm{ST}}=0\right) . Q_{E}$ and $Q_{W}$ are the heat coming in and coming out of the cell centered on $P$ from the west and the east, respectively. $Q_{J}$ and $Q_{\mathrm{ST}}$ are the heat produced by Joule effect and being stored in the cell, respectively.

\section{B. Improved structure}

To take into account the heat transfer in the improved PC-RAM structure involving the low thermal conductive pseudo-TiN electrode [Fig. I(b)], we have solved the timedependent heat transfer problem by a numerical simulation technique based on the finite-volume method using a onedimensional grid (Fig. 2). The grid is made of cells $P$ centered on $P$ of cross section $S$ and of width $d_{X}$ that are side by side with cells $W$ and $E$. In each cell, a linear equation is derived from the condition that the sum of the heat coming in, coming out, being stocked, and created is zero. The temperature $T_{P}$ at the time $t+d t$ in each cell centered on $\mathrm{P}$ is calculated from a linear equation, function of the temperatures $T_{W}$ and $T_{E}$ of the next cells, and of the temperature $T_{a}$ of the cell centered on $\mathrm{P}$ at the time $t$ :

$$
T_{p}=a_{W} T_{W}+a_{E} T_{E}+a_{S T} T_{a}+\gamma
$$

where

$$
\begin{aligned}
& a_{E}=q_{E E} / q_{P} \text { and } a_{W}=-q_{W W} / q_{P}, \\
& a_{\mathrm{ST}}=\rho c_{P} d_{X} / d t q_{P}, \\
& \gamma=-J^{2} d_{X} / \sigma q_{P},
\end{aligned}
$$

with

$$
\begin{aligned}
& q_{W P}=\frac{\left(g_{P W}-1\right) \lambda(P) S}{d_{X W}} \text { and } q_{W W}=\frac{g_{W P} \lambda(P) S}{d_{X W}} \\
& q_{E P}=\frac{\left(1-g_{P E}\right) \lambda(P) S}{d_{X E}} \text { and } q_{E E}=-\frac{g_{E P} \lambda(P) S}{d_{X E}} \\
& q_{P}=+q_{W P}-q_{E P}-\rho c_{P} d_{X} / d t
\end{aligned}
$$

and

$$
\begin{aligned}
g_{P E} & =\frac{\lambda(P) d_{X W}(E)}{\lambda(P) d_{X W}(E)+\lambda(E) d_{X E}(P)}, \\
g_{E P} & =\frac{\lambda(E) d_{X E}(P)}{\lambda(P) d_{X W}(E)+\lambda(E) d_{X E}(P)},
\end{aligned}
$$


TABLE 1. Thermal conductivity measurement results at $300 \mathrm{~K}$. The measurements have been made by the so-called $3 \omega$ method $2 \mathrm{~b}$, d, $\mathrm{P}_{1}$, and TCR are the width of the metallic strip, the distance between the two voltage probes, the average heating power per unit of length and, the temperature coefficient of resistance of the microheater, respectively. $\Delta \mathrm{T}_{\mathrm{Si}}, \Delta \mathrm{T}_{\mathrm{ins}}$, and $\Delta \mathrm{T}_{\mathrm{r}}$ are the temperature rises measured at the microlieater, due to the thermal resistance of the substrate, the insulating layer and the $\mathrm{Ge}_{2} \mathrm{Sb}_{2} \mathrm{Te}_{5}$ or TiN films, respectively. $\lambda$ is the thermal conductivity extracted from the measurements.

\begin{tabular}{|c|c|c|c|c|c|c|c|c|}
\hline & Insulating material & Heater geometry & $\mathrm{P}\left[\mathrm{W} \mathrm{m}^{-1}\right]$ & $\operatorname{TCR}\left[K^{-1}\right]$ & $\Delta \mathrm{T}_{\mathrm{Si}}[\mathrm{K}]$ & $\Delta \mathrm{T}_{\mathrm{ins}}[\mathrm{K}]$ & $\Delta \mathrm{T}_{\mathbf{r}}[\mathrm{K}]$ & $\lambda\left[\mathrm{W} \mathrm{m}^{-1} \mathrm{~K}^{-1}\right]$ \\
\hline \multirow[t]{3}{*}{$\mathrm{ZnS}: \mathrm{SiO}_{2}(100 \mathrm{~nm})$} & $\because$ & $\begin{aligned} 2 b & =20 \mu \mathrm{m} \\
d & =2 \mathrm{mmm}\end{aligned}$ & 49.3 & $1.40 \times 10^{-3}$ & 0.44 & 0.50 & $\ldots$ & 0.49 \\
\hline & $\cdots$ & $\begin{array}{c}2 b=5.94 \mu \mathrm{mn} \\
d=1 \mathrm{~mm}\end{array}$ & 50.2 & $1.49 \times 10^{-3}$ & 0.58 & 0.84 & $\ldots$ & 0.46 \\
\hline & $\cdots$ & $\begin{array}{c}2 b=3.24 \mu \mathrm{m} \\
d=1 \mathrm{~mm}\end{array}$ & 10.3 & $1.48 \times 10^{-3}$ & 0.13 & 0.66 & $\ldots$ & 0.48 \\
\hline \multirow[t]{3}{*}{$\mathrm{SiO}_{2}(100 \mathrm{~nm})$} & $\cdots$ & $\begin{aligned} 2 b & =20 \mu \mathrm{m} \\
d & =2 \mathrm{~mm}\end{aligned}$ & 44.8 & $1.67 \times 10^{-3}$ & 0.40 & 0.66 & $\ldots$ & 1.40 \\
\hline & $\cdots$ & $\begin{array}{c}2 b=4.8 \mu \mathrm{m} \\
d=1 \mathrm{~mm}\end{array}$ & 23.1 & $1.60 \times 10^{-3}$ & 0.28 & 0.36 & $\ldots$ & 1.30 \\
\hline & $\cdots$ & $\begin{array}{c}2 b=1.3 \mu \mathrm{m} \\
d=1 \mathrm{~mm}\end{array}$ & 10.2 & $1.57 \times 10^{-3}$ & 0.15 & 0.60 & $\cdots$ & 1.25 \\
\hline \multirow[t]{2}{*}{ Amorphous $\mathrm{Ge}_{2} \mathrm{Sb}_{2} \mathrm{Te}_{5}(300 \mathrm{~nm})$} & $\mathrm{ZnS}: \mathrm{SiO}_{2}(100 \mathrm{~nm})$ & $\begin{aligned} 2 b & =20 \mu \mathrm{m} \\
d & =2 \mathrm{~mm}\end{aligned}$ & 29.2 & $1.47 \times 10^{-3}$ & 0.26 & 0.31 & 1.86 & 0.24 \\
\hline & & $\begin{array}{c}2 b=5.94 \mu \mathrm{m} \\
d=1 \mathrm{~mm}\end{array}$ & 12.4 & $1.51 \times 10^{-3}$ & 0.11 & 0.44 & 2.61 & 0.24 \\
\hline \multirow[t]{2}{*}{ Crystallized $\mathrm{Ge}_{2} \mathrm{Sb}_{2} \mathrm{Te}_{5}(280 \mathrm{~mm})$} & $\mathrm{ZnS}: \mathrm{SiO}_{2}(100 \mathrm{~mm})$ & $\begin{aligned} 2 b & =20 \mu \mathrm{m} \\
d & =2 \mathrm{~mm}\end{aligned}$ & 29.2 & $1.41 \times 10^{-3}$ & 0.26 & 0.3 & 1.58 & 0.26 \\
\hline & & $\begin{array}{c}2 b=5.94 \mu \mathrm{m} \\
d=1 \mathrm{~mm}\end{array}$ & 12.4 & $1.32 \times 10^{-3}$ & 0.14 & 0.44 & 2.04 & 0.29 \\
\hline \multirow[t]{3}{*}{$\operatorname{TiN}(300 \mathrm{~nm})$} & $\mathrm{SiO}_{2}(100 \mathrm{~nm})$ & $\begin{aligned} 2 b & =10 \mu \mathrm{m} \\
d & =2 \mathrm{~mm}\end{aligned}$ & 37.8 & $1.49 \times 10^{-3}$ & 0.39 & 0.29 & 0.12 & 10 \\
\hline & & $\begin{array}{c}2 b=9.5 \mu \mathrm{m} \\
d=2 \mathrm{~mm}\end{array}$ & 13.6 & $1.46 \times 10^{-3}$ & 0.15 & 0.12 & 0.03 & 11 \\
\hline & & $\begin{array}{c}2 b=2.17 \mu \mathrm{m} \\
d=2 \mathrm{~mm}\end{array}$ & 4.44 & $1.50 \times 10^{-3}$ & 0.06 & 0.16 & 0.04 & 15 \\
\hline
\end{tabular}

$$
\begin{aligned}
g_{P W} & =\frac{\lambda(P) d_{X E}(W)}{\lambda(P) d_{X E}(W)+\lambda(W) d_{X W}(P)}, \\
g_{W P} & =\frac{\lambda(W) d_{X W}(P)}{\lambda(P) d_{X E}(P)+\lambda(W) d_{X W}(P)} .
\end{aligned}
$$

In these equations $\rho, c_{p}$, and $\lambda(P)$ are the density, heat capacity, and the thermal conductivity in the cell $P$, respectively. $d_{X W}(E), d_{X E}(P), d_{X E}(W)$, and $d_{X W}(P)$ refer to the lengths shown in Fig. 2.

The simulation takes place on half of a PC-RAM cell $(x \geqslant 0)$ described in Fig. 1(b). The linear Eq.(4) derived with adiabatic (heat flux $=0$ ) and isothermal boundary ( $T$ $=300 \mathrm{~K})$ conditions at $x=0$ and $x=+1$, respectively, form a matrix that is solved with an iterative process based on Gauss-Seidel method. ${ }^{13}$

\section{RESULTS AND DISCUSSION}

\section{A. Thermal conductivity measurements}

The measurement parameters and the thermal conductivity measurement results are presented in Table I. It includes the results obtained on the insulating layers $\left(\mathrm{ZnS}: \mathrm{SiO}_{2}\right.$ and $\left.\mathrm{SiO}_{2}\right)$, the $\mathrm{PC}$ material $\left(\mathrm{Ge}_{2} \mathrm{Sb}_{2} \mathrm{Te}_{5}\right.$ in the amorphous or crystalline state) and the pseudoelectrode (TiN). It is worth noticing that the TCR measured on the Au/Ti films are about three times smaller than the TCR value of bulk gold $(4.0$ $\left.\times 10^{-3}\right) .{ }^{14}$ This decrease in TCR may likely be the result of charge-carrier scattering at the grain boundaries or of strains. $^{15}$

The thermal conductivites of $100-1 n m$-thick $\mathrm{ZnS}: \mathrm{SiO}_{2}$ layers, measured with three strips of widths $20,5.9$, and $3.2 \mu \mathrm{m}$, are $0.49,0.46$, and $0.48 \mathrm{~W} \mathrm{~m}^{-1} \mathrm{~K}^{-1}$, respectively. These values are in very good agreement with the results obtained by Kim et al. ${ }^{16}$ The thermal conductivities of 100 nm-thick $\mathrm{SiO}_{2}$ layers measured with three strips of widths $20,4.8$, and $1.3 \mu \mathrm{m}$ are $1.4,1.3$, and $1.25 \mathrm{~W} \mathrm{~m}^{-1} \mathrm{~K}^{-1}$, respectively. These thermal conductivity values are close to those reported for bulk or thermal silicon dioxide (1.4 $\mathrm{W} \mathrm{m}^{-1} \mathrm{~K}^{-1}$ ) (Refs. 9 and 1.7 ) but are significantly larger than those of PECVD silicon dioxide.

The thermal conductivities of amorphous 300-nm-thick $\mathrm{Ge}_{2} \mathrm{Sb}_{2} \mathrm{Te}_{5}$ films measured using 20 - and 5.94- $\mu \mathrm{m}$-wide strips are 0.235 and $0.24 \mathrm{~W} \mathrm{~m}^{-1} \mathrm{~K}^{-1}$, respectively. These values are very close to those obtained by Kim et al. ${ }^{16}$ even if our analysis of the experimental data does not take into account the thermal boundary resistance between $\mathrm{Zn}: \mathrm{SiO}_{2}$ and $\mathrm{Ge}_{2} \mathrm{Sb}_{2} \mathrm{Te}_{5}$ whereas the analysis of Kim et al. does.

The thermal conductivity values become slightly higher for 280-nm-thick-crystallized $\mathrm{Ge}_{2} \mathrm{Sb}_{2} \mathrm{Te}_{5}$ films measured with strips of the same width. Since the electrical resistivities of our amorphous and crystallized $\mathrm{Ge}_{2} \mathrm{Sb}_{2} \mathrm{Te}_{5}$ layers are high (see Table II), the electronic contribution to the total thermal conductivity deduced from the Wiedemann-Franz law is 
TABLE II. Room-temperature physical properties of the materials used for the simulations. $\sigma$ is the electrical conductivity, $\rho$ the density, and $C_{p}$ the specific heat and $\lambda$ the thermal conductivity.

\begin{tabular}{|c|c|c|c|c|}
\hline Material & $\sigma\left[\Omega^{-1} \mathrm{~m}^{-1}\right]$ & $\rho\left[\mathrm{kg} \mathrm{m}^{-3}\right]$ & $\mathrm{C}_{\mathrm{p}}\left[\mathrm{J} \mathrm{kg}^{-1} \mathrm{~K}^{-1}\right]$ & $\lambda\left[W \mathrm{~m}^{-1} \mathrm{~K}^{-1}\right]$ \\
\hline Amorphous $\mathrm{Ge}_{2} \mathrm{Sb}_{2} \mathrm{Te}_{5}$ (film) & $\ldots$ & $6150^{i t}$ & $210^{\mathrm{a}}$ & $0.24^{\mathrm{b}}$ \\
\hline Crystallized $\mathrm{Ge}_{2} \mathrm{Sb}_{2} \mathrm{Te}_{5}$ (face cubic centered) & $10^{3 \mathrm{c}}$ & $6150^{\mathrm{a}}$ & $210^{\mathrm{a}}$ & $0.28^{\mathrm{b}}$ \\
\hline Crystallized $\mathrm{Ge}_{2} \mathrm{Sb}_{2} \mathrm{Te}_{5}$ (hexagonal compact) & $10^{3 \mathrm{c}}$ & $6150^{2}$ & $210^{\mathrm{a}}$ & $0.46^{\mathrm{d}}$ \\
\hline TiN (film) & $10^{5 \mathrm{~b}}$ & $5430^{\mathrm{n}}$ & $784^{e}$ & $15^{\mathrm{b}}$ \\
\hline \multicolumn{5}{|c|}{ 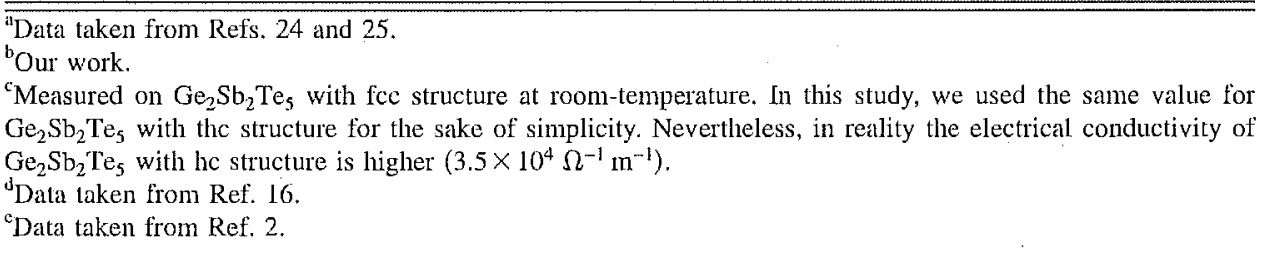 } \\
\hline
\end{tabular}

negligible. Consequently, the thermal conductivity values of our crystallized $\mathrm{Ge}_{2} \mathrm{Sb}_{2} \mathrm{Te}_{5}$ films can be directly compared to the values of the lattice thermal conductivity of wellcrystallized bulk material reported by Konstantinov et al. ${ }^{18}$ and to the thermal conductivity values of crystallized $\mathrm{Ge}_{2} \mathrm{Sb}_{2} \mathrm{Te}_{5}$ films reported by Kim et al. ${ }^{16}$ for whom the electronic contribution was also negligible. It, however, turned out that the values we found are about two times lower than those reported by these authors. This discrepancy may be explained by the obtaining of different crystallographic structures induced by the employment of different annealing temperatures. By the way, our anmealing treatment was performed at $480 \mathrm{~K}$ for $30 \mathrm{~min}$ whereas it was carried out at 550 $\mathrm{K}$ for $1 \mathrm{~min}$ by Kim et al., resulting in a smaller decrease in thickness ( $7 \%$ vs $10 \%$ ) too. Friedrich et al. ${ }^{19}$ and Yamada et $\mathrm{al}^{3}$ reported the obtaining of a rocksalt structure (fcc) for films annealed at 470 and $450 \mathrm{~K}$, respectively, whereas the temperatures found for the transition from the rocksalt to the hexagonal structure were 610 and $500 \mathrm{~K}$. Figure 3 shows the XRD patterns of an as-deposited $\mathrm{Ge}_{2} \mathrm{Sb}_{2} \mathrm{Te}_{5}$ film and of films annealed at 480 and $550 \mathrm{~K}$. An analysis of the peak diffractions obtained with the film annealed at $480 \mathrm{~K}$ for $30 \mathrm{~min}$ identifies the crystal structure as being fcc. Additional very weakly intense peaks are obtained on the XRD patterns of the film annealed at $550 \mathrm{~K}$ for $1 \mathrm{~min}$, suggesting that a second hexagonal phase starts to grow at the expense of the material in the fcc structure. An additional effect of the increase of the annealing temperature is an enhancement of the

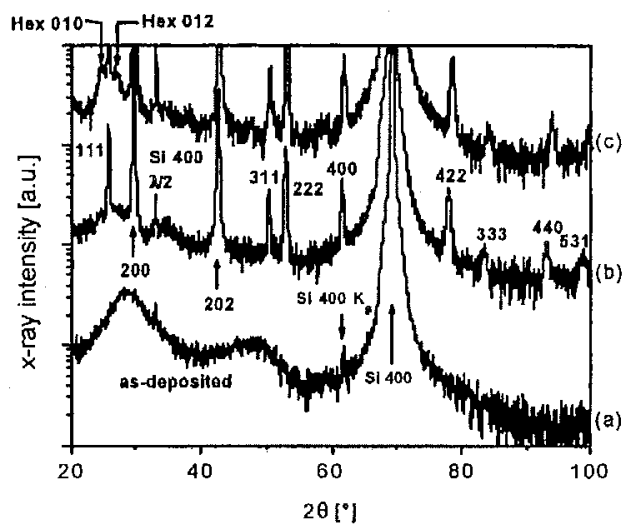

F[G. 3. X-ray diffraction patterns of $\mathrm{Ge}_{2} \mathrm{Sb}_{2} \mathrm{Te}_{5}$ films deposited on Si substrates. (a) as-deposited, (b) annealed at $480 \mathrm{~K}$, and (c) annealed at $550 \mathrm{~K}$. grain size ( $45-51 \mathrm{~nm}$, calculated by Scherrer's formula from the full width at half maximum of the $\langle 200\rangle$ peak of the fcc structure, the $K_{c 2}$ line being subtracted from $K_{\alpha 1}$ the line by deconvolution).

The thermal conductivity values of 300 -nm-thick titanium nitride films measured with $10,9.5$, and $2.17-\mu \mathrm{m}$-wide strips are 10,11 , and $15 \mathrm{~W} \mathrm{~m}^{-1} \mathrm{~K}^{-1}$. The difference in thermal conductivity measured with these different strips is quite large. This can be easily understood by the lowertemperature rise due to the TiN layers than due to the insulating layer. The thermal conductivity value obtained with the namrower strip is the most likely to be the most accurate. Therefore, this value will be taken in the next calculations. Much more accurate measurements could have been obtained using on membrane thermal conductivity. ${ }^{20}$ The thermal conductivity of our films is significantly lower than the thermal conductivity of bulk TiN nitride. ${ }^{21}$ The contribution of the electronic part to the total themal conductivity $\left(15 \mathrm{~W} \mathrm{~m}^{-1} \mathrm{~K}^{-1}\right)$ of the TiN films is about $0.8 \mathrm{~W} \mathrm{~m}^{-1} \mathrm{~K}^{-1}$. Therefore, the total thermal conductivity is essentially dominated by the phononic part.

It is worth noticing that the electrical resistivity of our TiN layers $(\rho=9 \mu \Omega \mathrm{m})$ is relatively large compared to the values found in the literature. ${ }^{22}$ This can be explained by the addition of oxygen in TiN which may change drastically the electrical properties, inducing a transition from the metallic to a semiconducting state. ${ }^{23}$ Actually, Rutherford backscattering spectroscopy showed that our films are strongly oxidized $\left(\mathrm{TiNO}_{0.5}\right)$.

\section{B. Heat transfer in PC-RAM cells}

The time $\left(t_{F}\right)$ needed to reach the melting temperature of the $\mathrm{PC}$ material $\left(T_{F}=916 \mathrm{~K}\right)$ and the maximum cooling speed reached after the switching off of the current have been calculated by solving by dichotomy $T\left(0, t_{F}\right)=T_{F}$ and by calculating, $\operatorname{Max}\left|\partial T_{2}\left(0, t>t_{F}\right) / \partial t\right|$, respectively. The crosssection area of the PC-RAM cells was considered to be $1 \mu \mathrm{m}^{2}$. The thermal properties of the PC material used in these calculations are shown in Table II and the results in Table III. The calculations have been done with two reset currents of intensities 4 and $8 \mathrm{~mA}$ and with $\mathrm{Ge}_{2} \mathrm{Sb}_{2} \mathrm{Te}_{5}$ material in the fcc and hexagonal crystallographic structures. Our calculation shows that a decrease of the thermal conduc- 
TABLE III. Influence of the thermal conductivity of the PC material on the time $t_{F}$ needed to reach the melting temperature $T_{F}$ and on the cooling speed calculated with formula (2) and (3), respectively for various switching currents I. The electrodes are assumed to be perfect heat sinks at the temperature $300 \mathrm{~K}$. If the melting temperature is not reached, the maximal temperature reached instead of $t_{F}$ is reported in brackets. The maximum cooling speed is reached at a time reported in brackets that lag behind $t_{F}$.

\begin{tabular}{cccc}
\hline \hline & $\mathrm{I}(\mathrm{mA})$ & $\iota_{F}(\mathrm{~ns})$ & Cooling speed $(\mathrm{K} / \mathrm{s})$ \\
\hline Crystallized $\mathrm{Ge}_{2} \mathrm{Sb}_{2} \mathrm{Te}_{5}$ (face centered cubic) & 8 & 12.7 & $-1.1 \times 10^{10}[25 \mathrm{~ns}]$ \\
& 4 & 13.2 & $-1.2 \times 10^{10}[146 \mathrm{~ns}]$ \\
Crystallized $\mathrm{Ge}_{2} \mathrm{Sb}_{2} \mathrm{Te}_{5}$ (hexagonal compact) & 8 & 13.6 & $-1.8 \times 10^{10}[20 \mathrm{~ns}]$ \\
& 4 & {$[691 \mathrm{~K}]$} & $\cdots$ \\
\hline
\end{tabular}

tivity of the $\mathrm{PC}$ material from 0.46 to $0.28 \mathrm{~W} \mathrm{~m} \mathrm{~m}^{-1} \mathrm{~K}^{-1}$ does not decrease significantly $t_{F}$ for a current intensity of $8 \mathrm{~mA}$ This is because $t_{F}$ is so small that heat does not have time to spread significantly in the PC material. For a current intensity of $4 \mathrm{~mA}, T_{F}$ cannot be reached for a PC-RAM cell made of hexagonal $\mathrm{Ge}_{2} \mathrm{Sb}_{2} \mathrm{Te}_{5}$ whereas it takes about $142 \mathrm{~ns}$ for a PC-RAM cell made of fcc $\mathrm{Ge}_{2} \mathrm{Sb}_{2} \mathrm{Te}_{5}$. This result is interesting because it means that lower voltages (1.4 vs $2.8 \mathrm{~V}$ ) across the PC-RAM cells can be used. It is worth noticing that the maximum cooling speed after the reset current is switched from 8 to $0 \mathrm{~mA}$ is about two times lower when the thermal conductivity of the PC material is changed from 0.46 to $0.28 \mathrm{~W} \mathrm{~m}^{-1} . \mathrm{K}^{-1}$, i.e., when the crystallographic structure is changed from the hexagonal compact to the rocksalt structure.

The influence of the thermal resistance and heat capacitance induced by the pseudoelectrode made of titanium nitride was also studied by numerical simulations. The thermal properties of the pseudo-TiN electrode are given in Table II and the thermal properties of the PC material are those of the material with the fcc crystallographic structure. The temperature profiles were plotted for current intensities of 4 and 8 $\mathrm{mA}$ and for various thicknesses of the pseudoelectrodes (Fig. 4) at the time $t_{F}$ needed by the PC-RAM cell to reach the melting temperature in its center, for an electrode $1 \mu \mathrm{m}$ in thickness. Once again, if the reset current is $8 \mathrm{~mA}$, the tem- perature profile calculated with Eq. (2) and by numerical simulation is almost the same whatever the electrode thickness is [Fig. 4(a)]. If the reset current is $4 \mathrm{~mA}$, the change in the temperature profile is noticeable [Fig. 4(b)]. The time needed to reach the melting temperature is significantly lower with a 1 - $\mu \mathrm{m}$-thick electrode than when the electrode is considered as a perfect heat sink (94.7 ns vs 142 ns, see Table III). More generally, when the TiN thickness is larger than the thermal penetration length, i.e., $\sqrt{\kappa_{E} t_{F}}$, where $\kappa_{E}$ is the thermal diffusivity of the pseudoelectrode, the temperature profile in the PC material is almost unaffected when the electrode thickness is changed. Obviously, materials used to make pseudoelectrodes in PC-RAM cells must have even lower thermal conductivity. Nevertheless, the cooling speed decreases when the thermal conductivity of the TiN electrode is decreased and amorphization may not take place. For example, when the switching currents are 4 and $8 \mathrm{~mA}$, with a 1000 -nm-thick pseudoelectrode made of TiN, the maximum cooling speeds are about $1.0 \times 10^{10} \mathrm{~K} / \mathrm{s}$. These are slightly slower than when the pseudoelectrodes are perfect heat sinks.

\section{CONCLUSIONS}

The thermal conductivity of $\mathrm{ZnS}: \mathrm{SiO}_{2}, \mathrm{SiO}_{2}, \mathrm{Ge}_{2} \mathrm{Sb}_{2} \mathrm{Te}_{5}$, and $\mathrm{TiN}$ thin films has been

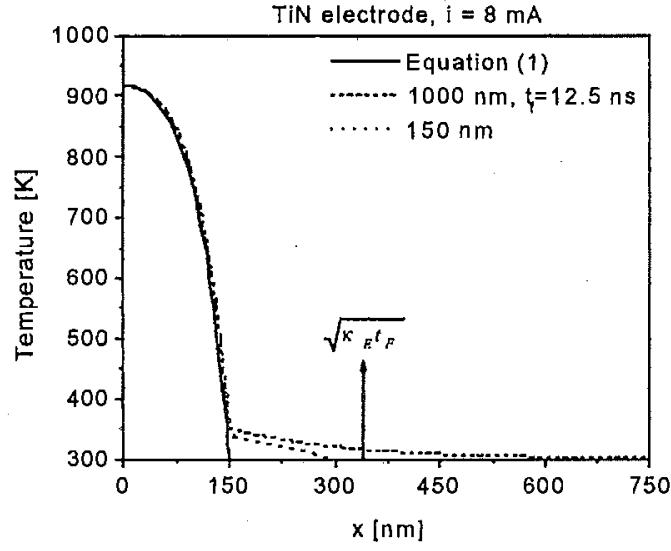

(a)

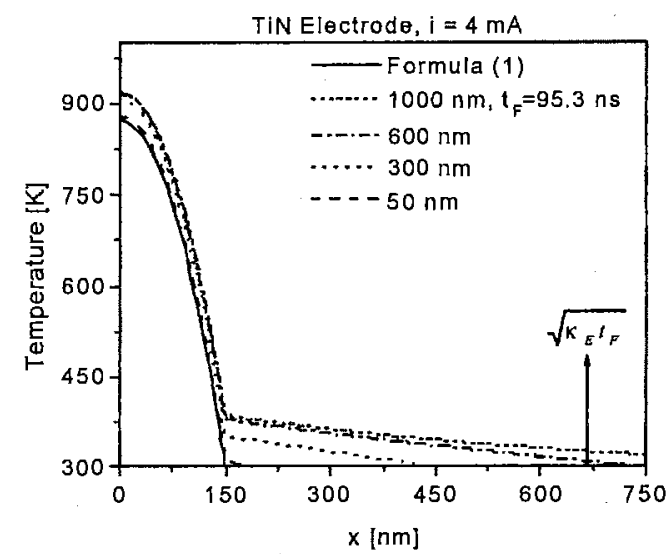

(b)

FIG. 4. Temperature profiles along the $x$ axis of half of a PC-RAM cell, constituted of a 300 nm-thick Ge $\mathrm{Sb}_{2} \mathrm{Te}_{5}$ latyer with the rock salt structure sandwiched by TiN layers of different thicknesses. The surface contact between the TiN pseudoelectrode and the phase change material is $1 \mu m^{2}$. The profiles of figures $a$ and $b$ ire obtained for reset currents of 4 and $8 \mathrm{~mA}$ and durations of 94.7 and $12.7 \mathrm{~ns}$, respectively. These are the times necessary for the temperature in the center of the cell with $1-\mu$ m-thick electrode to reach the melting temperature. The solid lines are obtained using Eq. (3) assuming that the electrodes are perfect heat sinks at $T=300 \mathrm{~K}$. The thermal penetration length at the time $t_{F}$ is $\sqrt{\kappa_{E} t_{F}}$, where $\kappa_{E}$ is the thermal diffusivity of the TiN electrode. 
measured by the $3 \omega$ method. We found that the thermal conductivities of amorphous and rocksalt-crystallized $\mathrm{Ge}_{2} \mathrm{Sb}_{2} \mathrm{Te}_{5}$ are 0.24 and $0.28 \mathrm{~W} \mathrm{~m}^{-1} \mathrm{~K}^{-1}$, respectively. The thermal conductivity of $\mathrm{Ge}_{2} \mathrm{Sb}_{2} \mathrm{Te}_{5}$ with the rocksalt structure is significantly lower than the reported values for the same material with a hexagonal crystallographic structure $\left(0.46 \mathrm{~W} \mathrm{~m}^{-1} \mathrm{~K}^{-1}\right)$. The thermal conductivity of oxidized TiN films $\left(15 \mathrm{~W} \mathrm{~m}^{-1} \mathrm{~K}^{-1}\right)$ is significantly lower than most of the reported values for bulk titanium nitride materials and its electrical resistivity is higher $(9 \mu \Omega \mathrm{m})$.

Analytical formula and numerical modeling have been developed taking into account the heat transfer by conduction and neglecting the heat of fusion of the PC material. They have been used to obtain the time-dependent temperature profiles in PC-RAM cells. It is further assumed that the electrodes are perfect heat sinks when deriving the analytical formula. It is concluded that a decrease in the thermal conductivity of the PC material or of the TiN pseudoelectrode improves the performance of PC-RAM cells only for long reset current duration of low intensity. The optimal pseudoelectrode thickness is about the thermal penetration length in the electrode at the time needed to reach the melting temperature of the PC material for a given reset current.

\section{ACKNOWLEDGMENTS}

The authors would like to thank François Mondon for discussions and critical reading of the manuscript, as well as Fabienne Ponthenier and Hemri Sibuet for fabrication of the dedicated batches.

'D.-H Kang, D.-H Ahn, K.-B Kim, J. F. Webb, and K.-W. Yi, J. Appl. Phys. 94, 3536 (2003).

${ }^{2}$ M. H. R. Lankhorst, R. A. M. Wolters, E. R. Meinders, and L. van Pietersen, in Proceedings of the Semicon Europa Conference, Munich, Ger- many, 1-3 April 2003, (unpublished), pp. 5-19.

${ }^{3}$ N. Yamada, E. Ohno, K. Nishiuchi, N. Akahira, and M. Takao, J. Appl. Phys. 69, 2849 (1991).

${ }^{4}$ N. Yamada, M. Otoba, K. Kawahara, N. Miyagawa, H. Oha, N. Akahira, and T. Matsunagn, Jpn. J. Appl. Phys., Part 1 37, 2104 (1998).

${ }^{5}$ H. Kado and T. Thoda, Jpn. J. Appl. Phys., Part 1 36, 523 (1997).

${ }^{6}$ E. R. Meinders, M. H. R. Lankhorst, H. J. Borg, and M. J. Dekker, Jpn. J. Appl. Phys., Part 1 40, 1558 (2001).

${ }^{7}$ D. G. Cahill, Rev. Sci. Instrum. 61, 802 (1990).

${ }^{8}$ S. M. Lee and D. G. Calnill, J. Appl. Phys. 81, 2590 (1997).

${ }^{9}$ A. Jacquot, B. Lenoir, A. Dauscher, M. Stölzer, and J. Meusel, J. Appl. Phys. 91, 4733 (2002)

${ }^{10}$ G. A. Slack, J. Appl. Phys. 35, 3460 (1964).

${ }^{1{ }^{1}}$ T. P. L. Pedersen, J. Kalb, W. K. Njoroge, D. Wamwangi, M. Wuttig, and F. Spaepen, Appl. Phys. Lett. 79, 3597 (2001).

${ }^{12}$ H. S. Carslaw and J, C. Jeager, Conduction of Heat in Solids (Oxford University Press, Oxford, 1959).

${ }^{13}$ S. V. Patankar, Numerical Heat Transfer and Fluid Flow (Hemisphere, London, 1980).

${ }^{14}$ E. A. Brandes, Smithells Metals Reference Book, 6th ed. (Butterworths, Londol1, 1983).

${ }^{15}$ C. R. Tellier and A. J. Tosser, Size Effects in Thin Films (Elsevier, Amsterdam, 1982).

${ }^{16}$ E.-K. Kinı, S.-I. Kwun, S.-M. Lee; H. Seo, and J.-G. Yoon, Appl. Phys. Lett. 76, 3864 (2000)

${ }^{17}$ K. E. Goodson, M. I. Flick, L. T. Su, and D. A. Antoniadis, Devices Lett. 14, 490 (1993).

${ }^{18}$ P. P. Konstantinov, L. E. Shelimova, E. S. Avilov, M. A. Kretova, and V. S. Zenskov, Inorg. Mater. 37, 662 (2001).

${ }^{19}$ I. Friedrich, V. Weidenhof, W. Njoroge, P. Franz, and M. Wuttig, J. Appl. Phys. 87, 4130 (2000).

${ }^{20}$ A. Jacquot, G. Chen, J.-P. Fleurial, A. Dauscher, and B. Lenoir, Sens. Actuators, A 117, 203 (2004).

${ }^{21}$ M. I. Aivazov and A. K. Muranevich, High Temp. 7, 830 (1969)

${ }^{22}$ K. Lal, A. K. Meikap, S. K. Chattopadhyay, S. K. Chatterjee, M. Ghosh, K. Baba, and R. Hatada, Physica B 307, 150 (2001).

${ }^{23}$ N. Martin, O. Banakh, A. M. E. Santo, S. Springer, R. Sanjinés, J. Takadoum, and F. Lévi, Appl. Surf. Sci. 185, 121 (2001).

${ }^{24}$ T. Ohta, K. Inoue, M. Uchida, K. Yoshioka, T. Akiyama, S. Furukawa, K. Nagata, and S. Nakamura, Jpn. J. Appl. Phys., Suppl. 28, 123 (1989).

${ }^{25}$ J. F. Shackelford and N. Alexander, CRC Materials Science and Engineering Handbook, 3rd ed. (CRC, Boca Raton, FL, 2001). 